\title{
Expert System for Integrated Control and Supervision of Dry-End Sections of Paper Machines
}

\author{
L. M. Aníbal Valenzuela, Senior Member, IEEE, John Martin Bentley, Life Fellow, IEEE, and \\ Robert D. Lorenz, Fellow, IEEE
}

\begin{abstract}
A rule-based expert system for the integrated control and supervision of the dry-end sections of a paper machine is proposed. This system is capable of recognizing all the normal and abnormal changes in process operating conditions, including acceleration of sections, threading of paper sheet, nip pressure activation, activation and deactivation of tension control loops, change of parent roll, and sheet break. A core part of the system is the supervision of the sensorless tension control of the dry-end sections, assuring its long-term stability.
\end{abstract}

Index Terms-Expert system, paper machine drive, sensorless tension control, tension control.

\section{INTRODUCTION}

$\mathbf{I}$ $\mathrm{N}$ a previous paper [1], the authors presented a novel sensorless tension control based on section torque commands, which is capable of properly estimating sheet tension even in the presence of section load variations and/or small or null differential tension. This control algorithm was evaluated in a three-section dry-end subsystem of a lightweight coated (LWC) paper machine.

This paper proposes an expert system that will improve the robustness of the sensorless tension control and assure its long-term stability (hours, days, weeks), making it more suitable for actual implementation.

The proposed expert system for integrated control and supervision of dry-end sections of paper machines is capable of recognizing the torque (current) and velocity profiles related to normal and abnormal changes in process operating conditions, and take actions according to the detected situation. Actions include messages to the operator of normal conditions, current status of process related sequences, warning messages of abnormal or potentially dangerous ongoing conditions, and tension control of the paper sheet using the sensorless control algorithms proposed in [1].

The proposed system belongs to the class of rule-based expert systems [2]-[5] and compares the acquired signals related to the

Paper PID 03-32, presented at the 2003 IEEE Pulp and Paper Industry Conference, Charleston, SC, June 15-20, and approved for publication in the IEEE TRANSACTIONS ON INDUSTRY APPLICATIONS by the Pulp and Paper Industry Committee of the IEEE Industry Applications Society. Manuscript submitted for review June 20, 2003 and released for publication November 18, 2003.

M. A. Valenzuela is with the Department of Electrical Engineering, University of Concepción, Concepción, Chile (e-mail: avalenz@die.udec.cl).

J. M. Bentley is at 6239 Clearview Drive, Manitowish Waters, WI 54545 USA.

R. D. Lorenz is with the Department of Mechanical Engineering and Department of Electrical and Computer Engineering,University of Wisconsin, Madison, WI 53706 USA (e-mail: lorenz@engr.wisc.edu).

Digital Object Identifier 10.1109/TIA.2004.824507 different events with the corresponding master patterns, using a predefined matching algorithm. Its event recognition capability is tested using recorded signals of an LW paper machine.

\section{PRocess-Related Torque AND Velocity Changes}

In order to develop the event recognition capability of the expert system, the different process operations that produce changes in the torque (current) of the sections need to be described, and their patterns acquired. The process disturbances that will be considered in the expert system are the following:

1) speed up of dry-end sections;

2) threading of the paper sheet through dry-end sections;

3) pressure activation in the calender section;

4) draw auxiliary signals;

5) activation of tension control in the calender;

6) activation of tension control in the reel;

7) change of the parent roll in the reel (automatic activation/deactivation of tension control in the reel);

8) cycle of parent roll formation;

9) change of operating speed;

10) sheet break.

For the evaluation of the torque (current) and speed waveforms during these events, the LWC paper machine reported in [1] is used. This is a 2500-feet-per-minute (FPM) or 762-meter-per-minute (MPM), 34-lb/3000- $\mathrm{ft}^{2}$ LWC paper machine. Its last three sections are shown in Fig. 1. Section motors are rated at $242 \mathrm{~kW}$ (M4: dryer), $117 \mathrm{~kW}$ (M5: calender), and 98.5 kW (M6: reel), respectively. Section loads and tension references are set according to TAPPI recommendations.

\section{A. Acceleration of Dry-End Sections}

During the starting up of the paper machine from a rest condition, each section is accelerated up to the operating (threading) speed following an s-ramp reference. Fig. 2 shows the current (torque) and speed plots during a 100-s ramp acceleration of the fifth dryer section of the LWC paper machine shown in Fig. 1 [1]. A possible trigger for this event by the expert system could be either the section- starting button, an increase in motor current (torque or torque command) or an increase in motor velocity.

\section{B. Threading of Paper Sheet}

Threading of the sheet on a modern paper machine generally involves a process in which the sheet is gradually widened from a leading tip to full width between the former and the press 


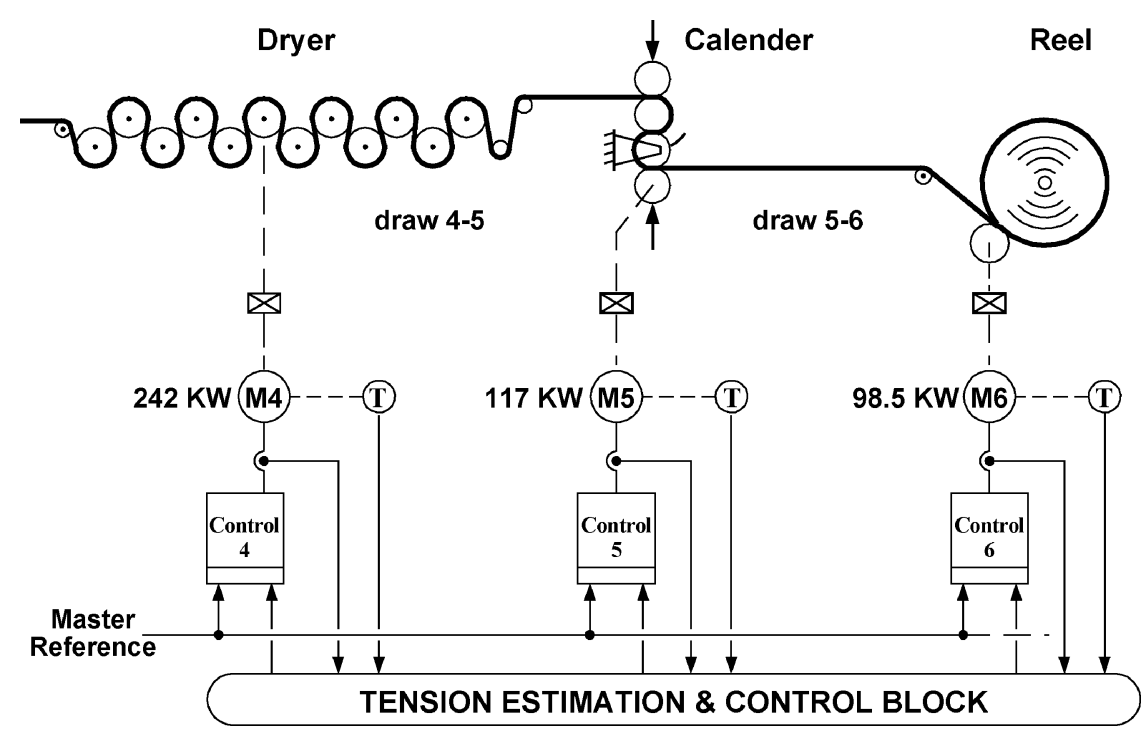

Fig. 1. Dry-end arrangement of a high-speed LWC paper machine [1].

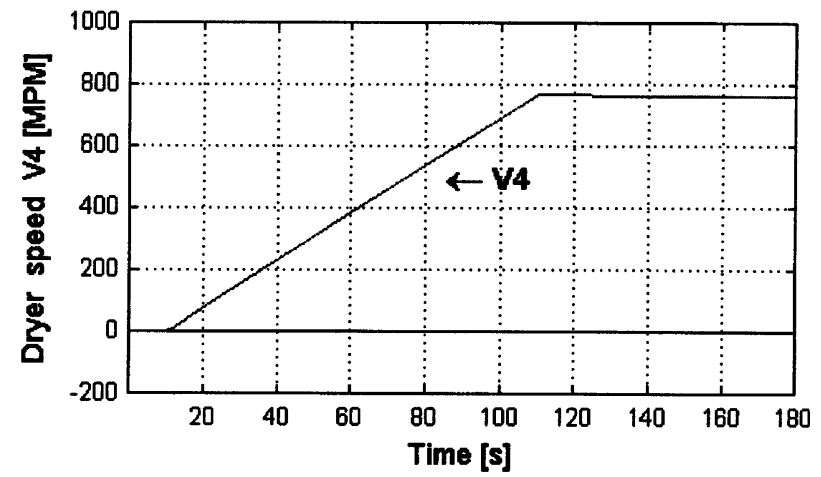

(a)

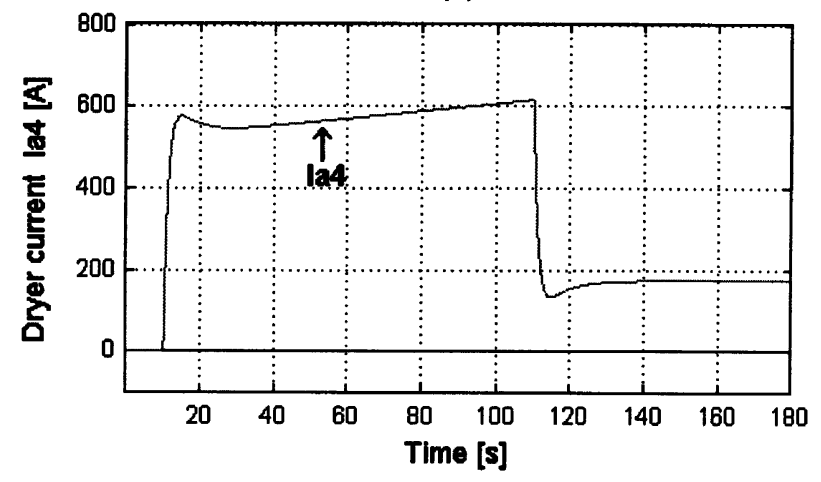

(b)

Fig. 2. Speed and current waveforms during the acceleration of the dryer section; (a) Dryer speed waveform. (b) Dryer current waveform.

group while the machine is operating at production speed. This threading/widening process will be completed automatically in the time required for the sheet to pass through the entire machine from the forming section to the reel. Consequently the widening process takes place in a few seconds in each individual draw span as it progresses through the machine.
After the full width sheet is nipped between the reel drum and spool, and depending on the process operating conditions, the operators will keep the calender and reel section in speed control, or will activate the tension control loops. If process conditions are not stable enough, the operator will keep these sections in speed control mode, and will manually adjust the draw references to control (indirectly) the sheet tension.

During the threading of the paper, and before the activation of the tension control loops, there is no significant change in the motor currents or motor speeds. This low tension widening event could be recognized by the change of state of the sheet break detectors. It is important for the expert system to recognize this event because after it, patterns of events 3 , 4 , or 5 are expected.

\section{Calender Pressure Activation}

After the sheet is threaded full width through the calender into the reel, the operating nip pressure is applied to the calender rolls. The pressure control activation produces a noticeable change in the torque (current) of the calender drive, increasing it to the normal running load (NRL) value (sheet tension components almost cancel).

Fig. 3 shows the current (torque) and speed in the calender drive of the LWC paper machine during the activation of the pressure. In these plots, a 2-s ramp pressure increase has been assumed. A trigger signal for this event could be taken from the pressure activation pushbutton in the operator console, or from the increase in the motor current. If pressure activation is initiated by the process control system, the same control signal itself can be used as the trigger.

\section{Draw Auxiliary Signals}

In the dry-end of a LWC paper machine, there are usually draw-adjust signals in the calender and reel drives. These signals 


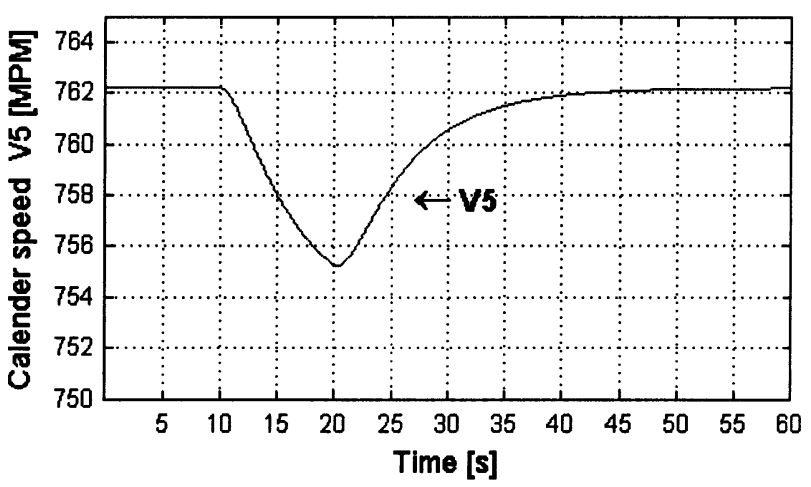

(a)

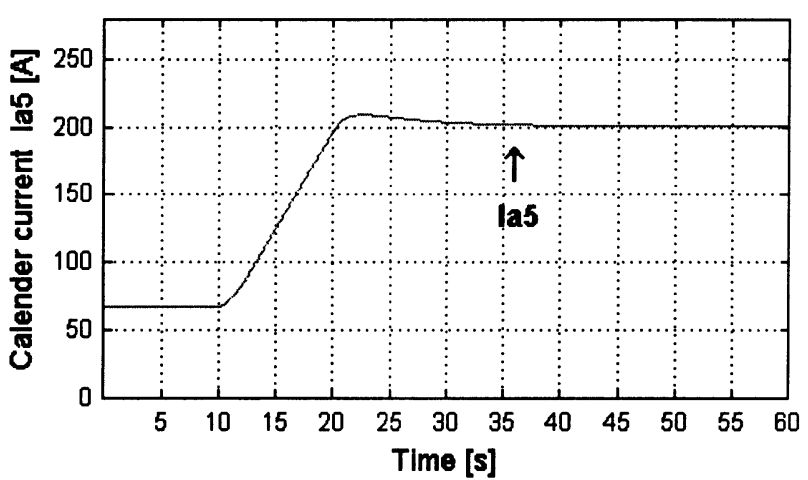

(b)

Fig. 3. Speed and current waveforms in the calender section during nip pressure activation. (a) Calender speed waveform. (b) Calender current waveform.

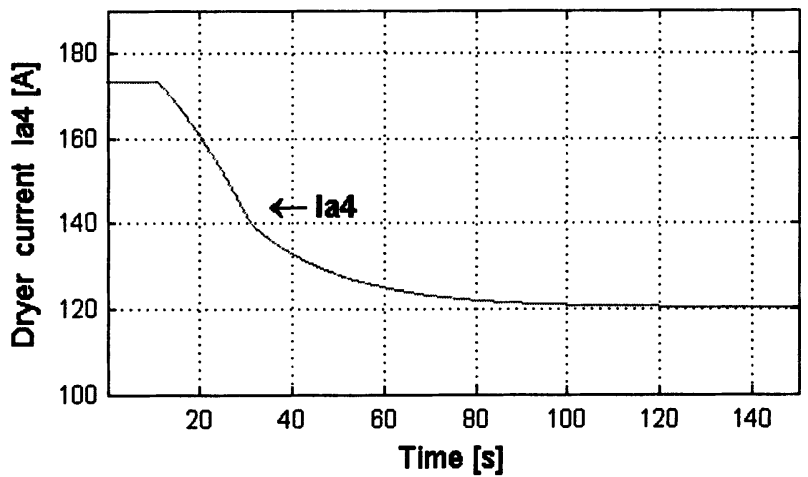

(a)

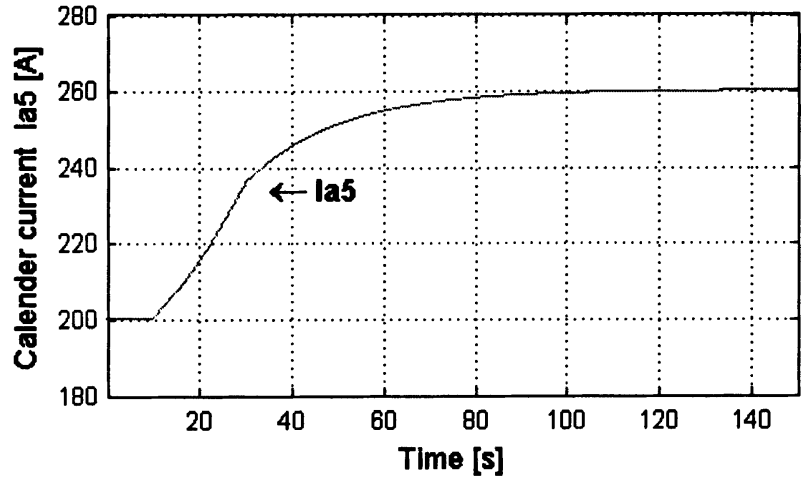

(b)

Fig. 4. Current waveforms in fifth dryer and calender sections during activation of tension control in the calender. (a) Dryer current waveform. (b) Calender current waveform.

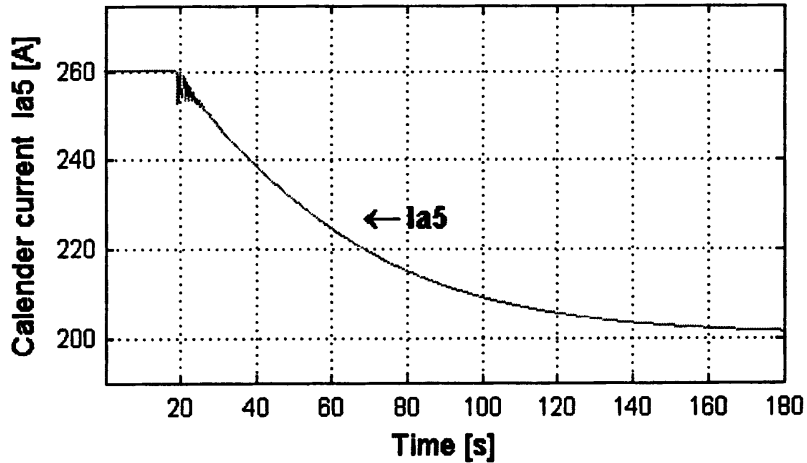

(a)

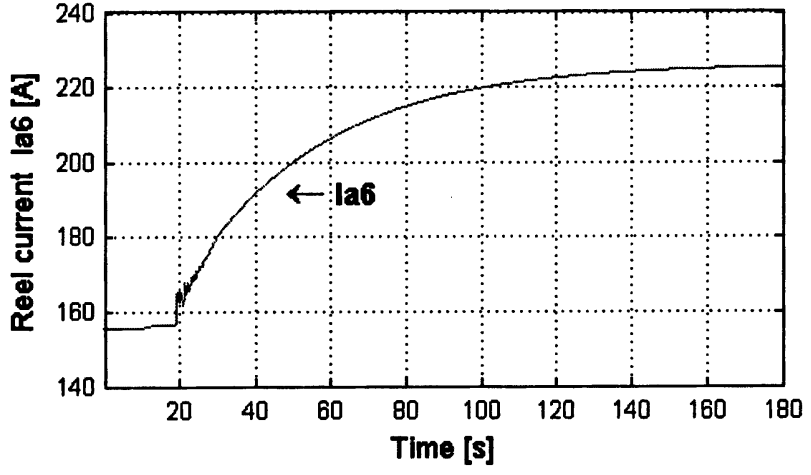

(b)

Fig. 5. Current waveforms in the calender and reel sections during activation of tension control in the reel. (a) Calender current waveform. (b) Reel current waveform.

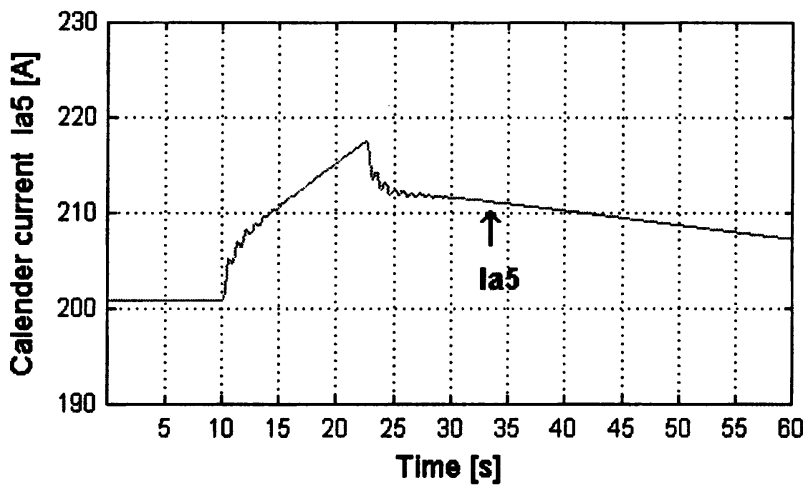

(a)

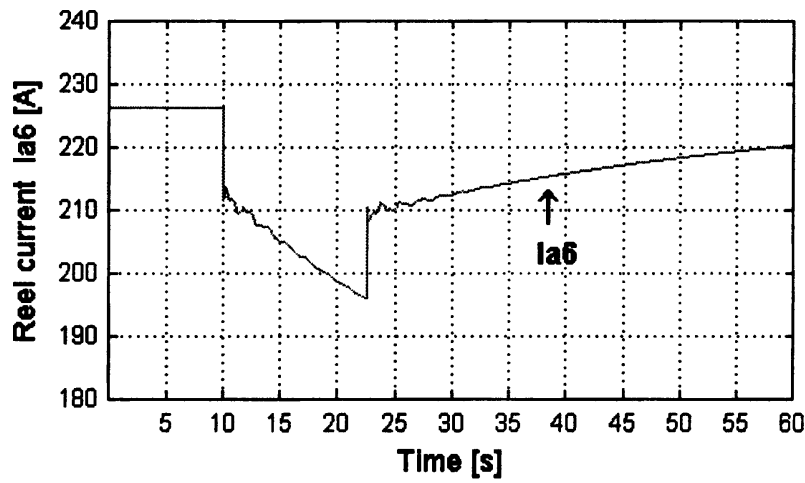

(b)

Fig. 6. Current waveforms in the calender and reel sections during the change of a parent roll. (a) Calender current waveform. (b) Reel current waveform. 


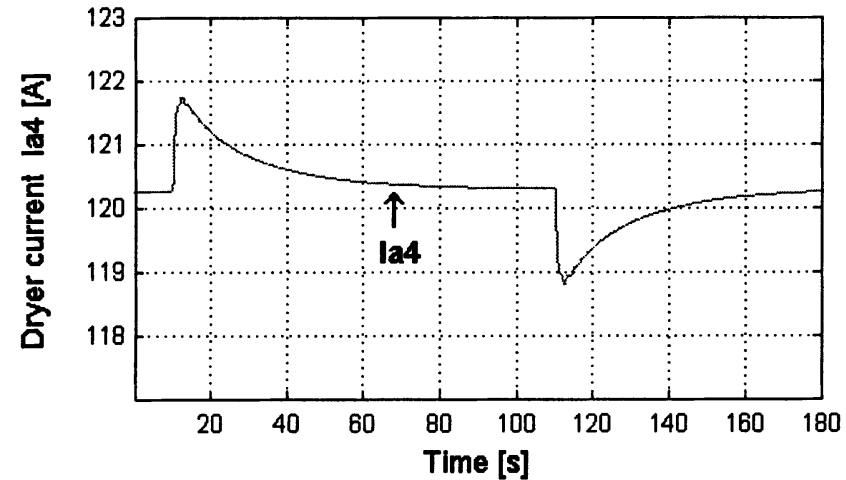

(a)

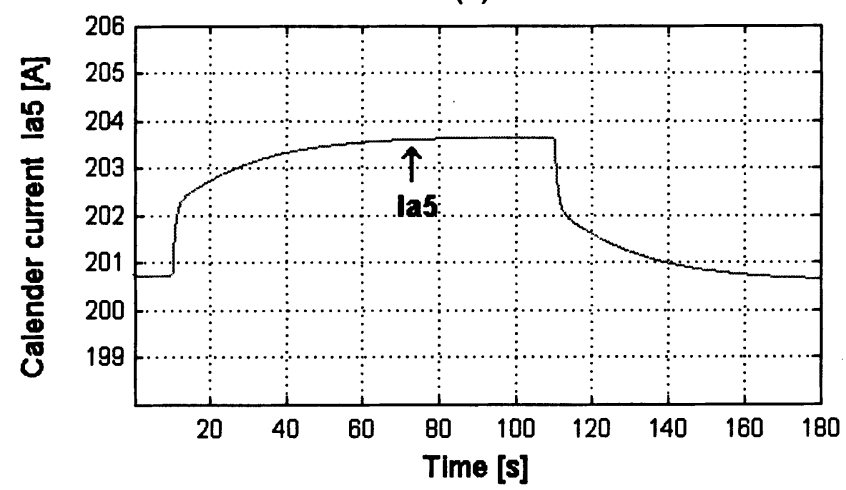

(c)

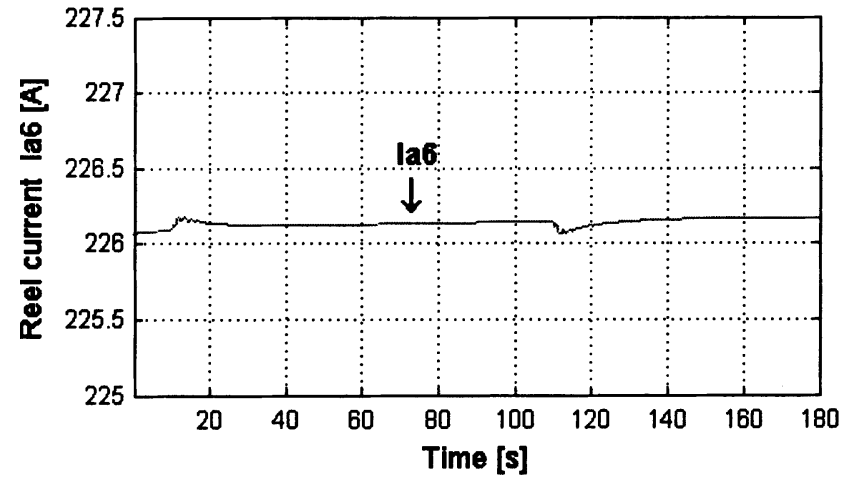

(e)

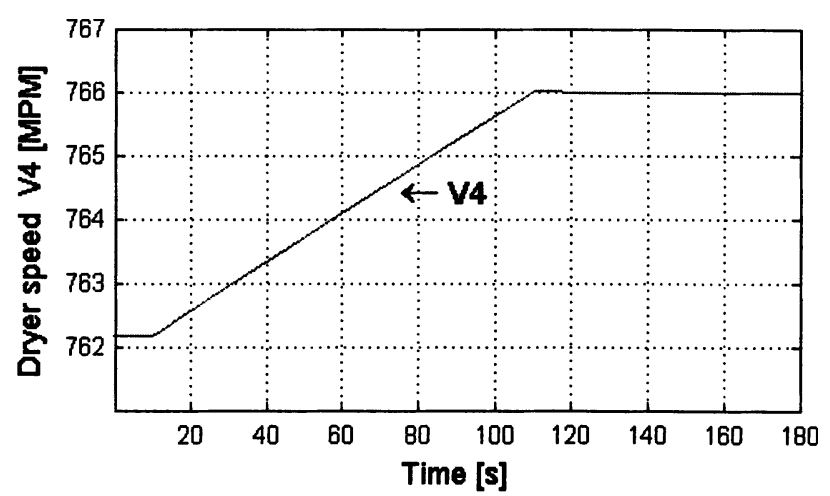

(b)

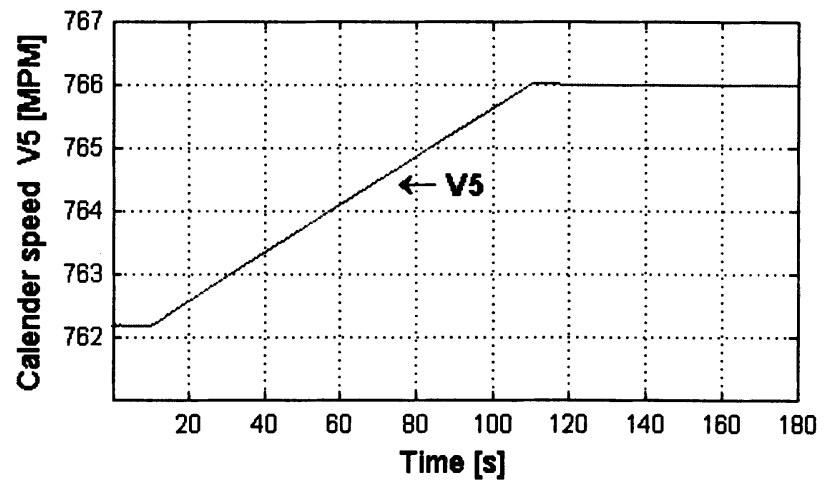

(d)

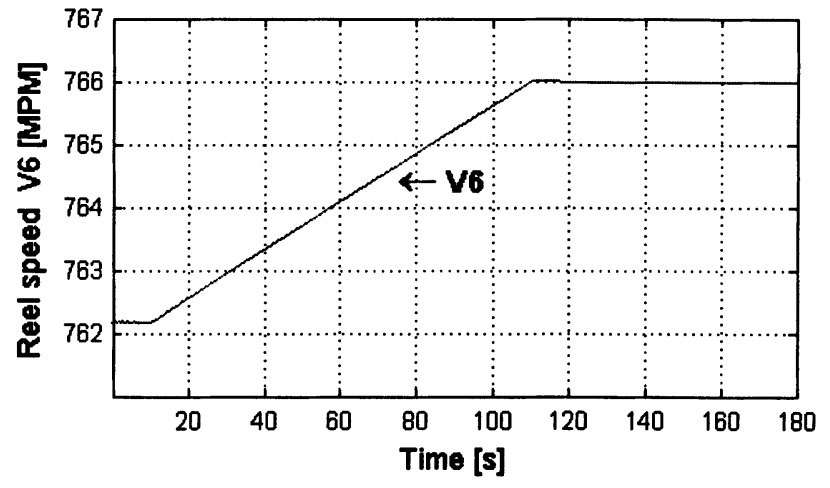

(f)

Fig. 7. Current and velocity waveforms in dry-end sections during a 5\% ramp increase. (a) Dryer current waveform. (b) Dryer speed waveform. (c) Calender current waveform. (d) Calender speed waveform. (e) Reel current waveform. (f) Reel speed waveform.

are used by the operator as an indirect sheet tension control, before the activation of the tension control loops. Each time the operator presses the draw pushbuttons in the operator console, it produces a speed increase (or decrement) in the section speed in steps of $0.01 \%-0.02 \%$. If the speed is increased and the sheet is running without slack, an increase in the corresponding motor current is also expected.

The reasonable trigger signal of this of event is the change in the draw pushbutton output.

\section{E. Activation/Deactivation of Tension Control in the Calender}

Tension control in the calender is usually activated by the operator at the time that the paper machine has been stabilized at the operating speed and the sheet starts to wind on the reel. When the tension control is activated, an increase in the torque (current) of the calender and a decrease in the torque (current) of the last dryer section should be expected.

The current in the calender prior to tension control activation depends (for a given paper grade) mainly on the value set in the draw signal. Operators may increase the draw value when they detect a slack, or bagging, sheet incoming to the calender rolls, which could produce sheet wrinkling, or a break due to a "calender cut."

The initial set point for the tension control loops in the calender can then be changed by the operators, based on experience for a given grade of paper. It is possible to know (compute) the expected current in the calender as a function of the tension setting.

Thus, using the draw and tension reference information, the expert system can estimate the initial and final current (torque) values expected during the tension activation event. 


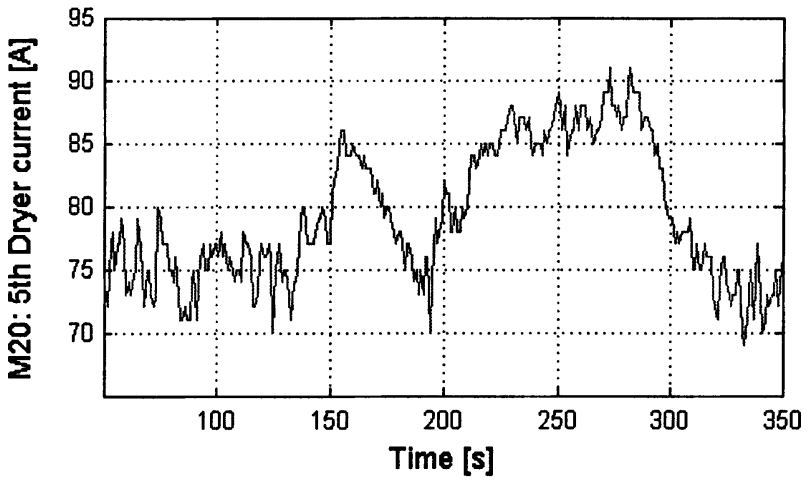

(a)

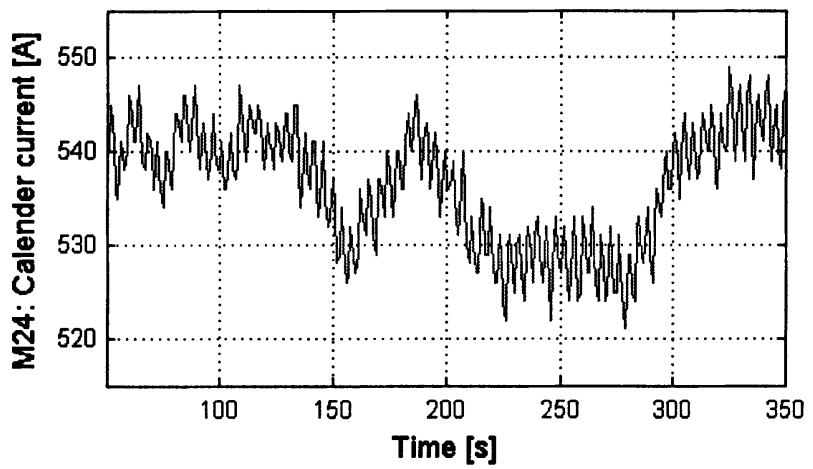

(b)

Fig. 8. Dryer and calender current data during temporary deactivation of tension control in the calender. (a) Dryer current data. (b) Calender current data.

When a sheet break occurs, the drive is switched back to speed control, but during the transient the speed increases, in an attempt to maintain the tension setting, and eventually reaches the speed limit.

Fig. 4 shows the currents in the fifth dryer and calender drives during the activation of the sensorless tension control loops in the calender. The trigger signal for this event could be the tension activation pushbutton.

\section{F. Activation of Tension Control in the Reel}

After completion of the threading process, as the sheet starts winding in the reel, tension control in the reel is usually activated automatically. The main purpose of this tension control is to assure that the sheet is being wound under a reasonable tension, resulting in a compact, well structured parent roll. Conventionally, this tension control is an indirect tension control, operating the reel drive in torque (current) control, with a speed limit.

During the activation of the reel tension control, the torque (current) in the reel increases and the torque (current) in the calender decreases due to the tension component which starts to pull the sheet out of the calender. As the tension settings of both tension loops are similar, the incoming and outgoing sheet tension components in the calender drive almost cancel; therefore, the torque (current) goes back to the initial value before the activation of the tension loop in the calender (nearly zero differential tension).

Fig. 5 shows the currents in the calender drive (Ia5) and in the reel drive (Ia6) after the activation of the reel sensorless tension loop. Current Ia6 increases about $60 \mathrm{~A}$, which is almost the

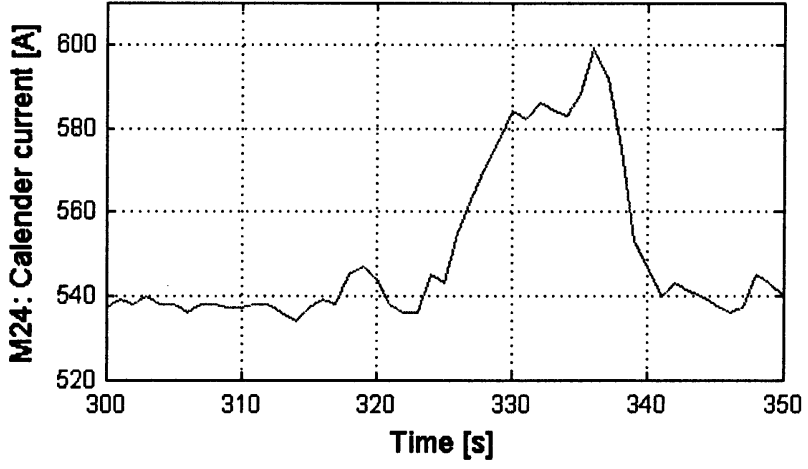

(a)

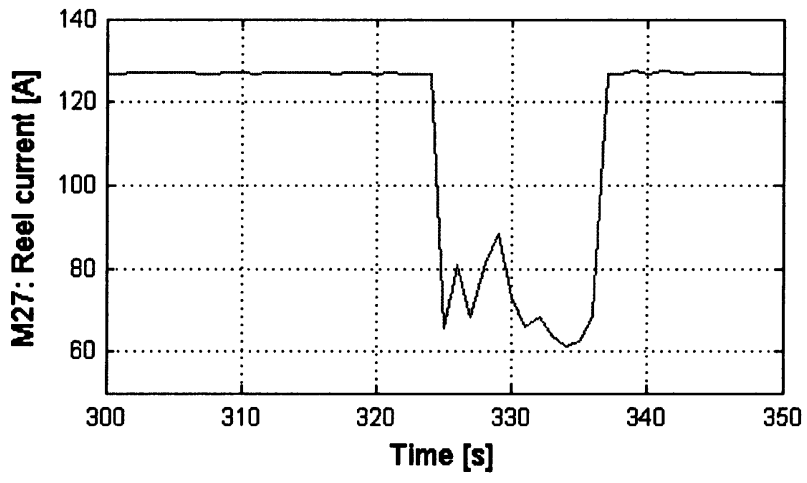

(b)

Fig. 9. Calender and reel current data during a change of the parent roll. (a) Calender current data. (b) Reel current data.

same decrement of current Ia5. Current Ia5 reaches about 200 A, which is nearly the same initial value as before the calender tension control activation.

\section{G. Change of Parent Roll in Reel}

After reaching the specified diameter, the parent roll is changed. This is done with the machine running at the operating speed, and the paper sheet is automatically cut and transferred to the incoming empty spool with an air blast and water spray. During the transfer process, which takes about 10 $\mathrm{s}$, the tension control in the reel is automatically deactivated, and then switched back to its operating setting. A rapid decrease and recovery of the torque (current) in the reel drive occurs. In the calender section, a similar change evolves in an opposite sense, as expected.

Fig. 6 shows this event in the LWC paper machine of [1]. Both current waveforms show the rapid changes expected. The trigger for this event could be the process control signal that activates the roll transfer, or a threshold signal for changes in the currents.

\section{H. Cycle of Parent Roll Formation}

Typically, this cycle lasts between 30-60 min, depending on the final parent roll diameter, machine speed, and sheet caliper. The beginning and ending of the cycle is defined by the change of parent rolls in the reel. The monitoring of these cycles allows the system to relate the sheet breaks in each parent roll, and to verify the torque (current) profile of the reel drive while the parent roll diameter is increasing. It is also used for the 


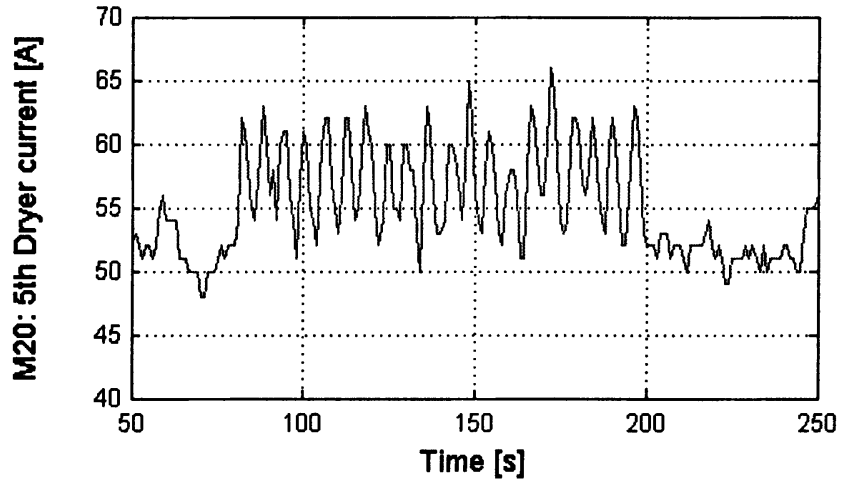

(a)

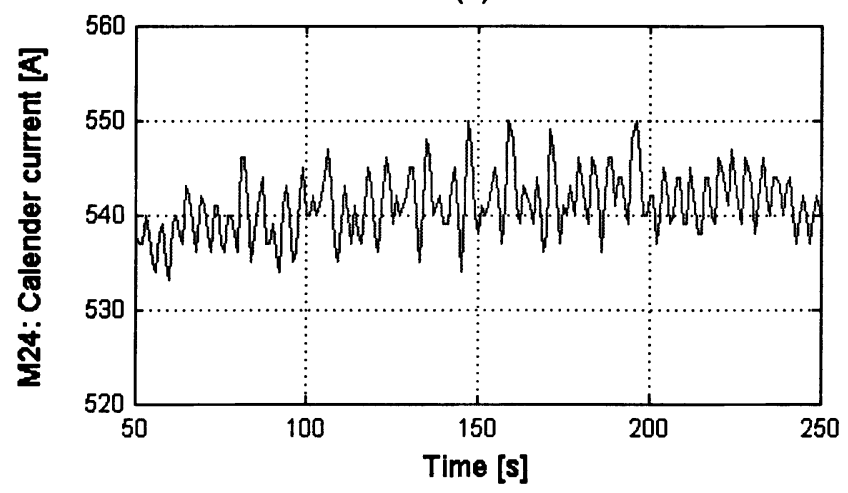

(c)

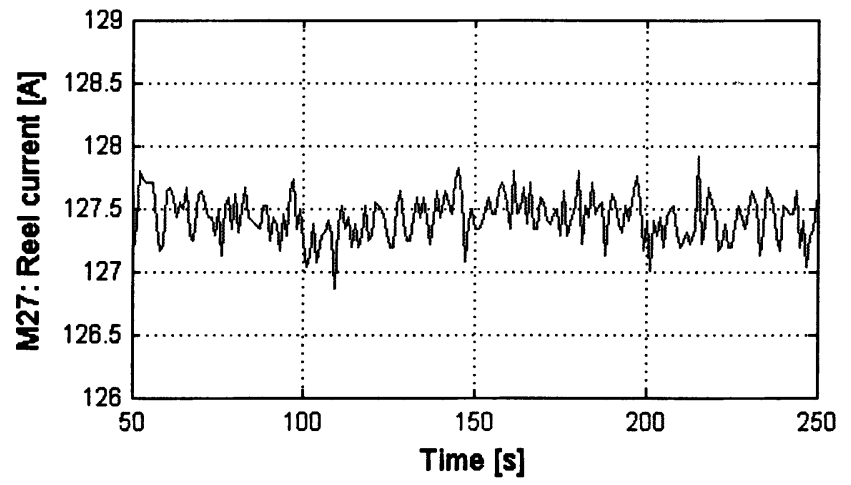

(e)

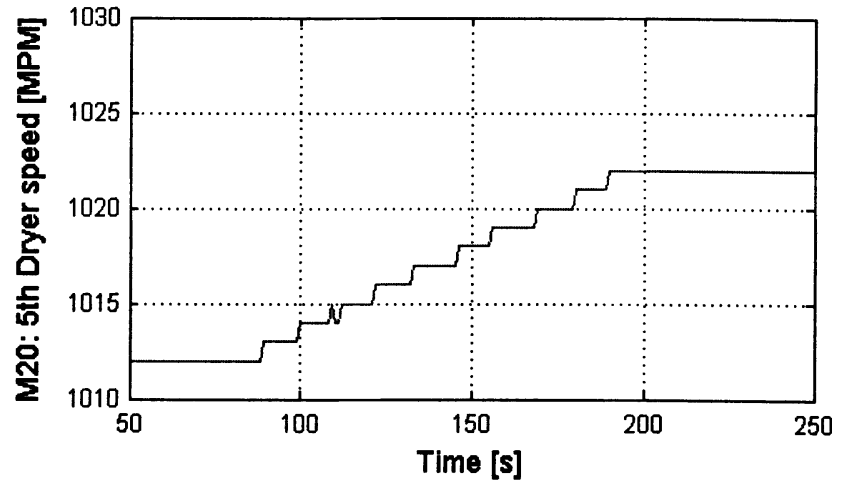

(b)

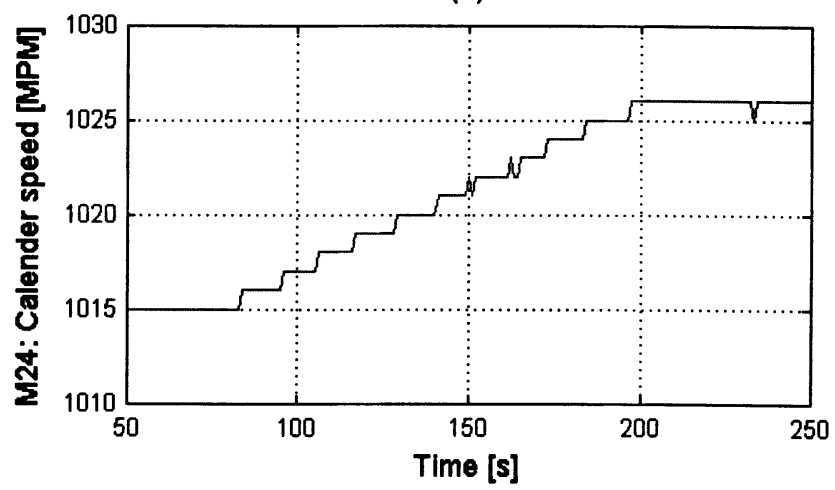

(d)

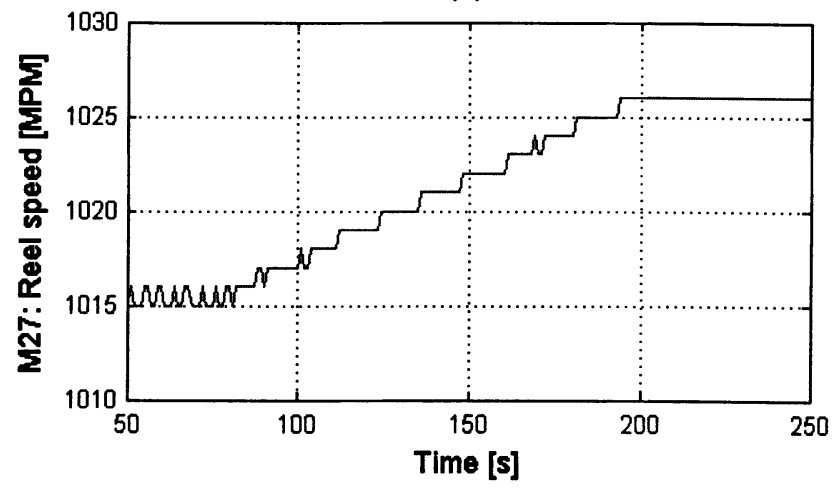

(f)

Fig. 10. Current and speed data during a 10-MPM operating speed increase. (a) Dryer current data. (b) Dryer speed data. (c) Calender current data. (d) Calender speed data. (e) Reel current data. (f) Reel speed data.

sensorless tension control supervision block to check any abnormal evolution of the dry-end current, to detect if a mechanical problem is developing.

\section{Change of Operating Speed}

Under normal, steady-state operating conditions, paper machines run at constant speed. The operating speed could require adjustment during disturbances in the fiber preparation area that influence freeness or consistency, or during an on-line change of production (change to a different paper grade, which is produced at a different machine velocity). The changes of the operating speed are done in steps of 5-10 MPM, using slow ramps (100 s).

Fig. 7 shows the velocities and currents in the dry-end sections during a 5\% ramp increase. The current in the calender section shows the largest increase, although the dryer section has the highest inertia [1]. This is explained because the dryer section tends to respond more slowly to the reference changes, and the calender section then assists the dryer through the sheet tension, increasing its own load.

\section{J. Sheet Break}

When a paper break occurs, the tension-controlled drives will no longer have a balanced torque load in each section and acceleration will occur. With a short delay, the sheet break detectors signal that a break has occurred and switch the drives back to speed control.

In the dryer section, when the sheet break reaches the controlled span, the outgoing sheet tension suddenly disappears; therefore, the current increases. Simultaneously, the speed will show a fast decrease followed by a recovery up to the operating speed. 


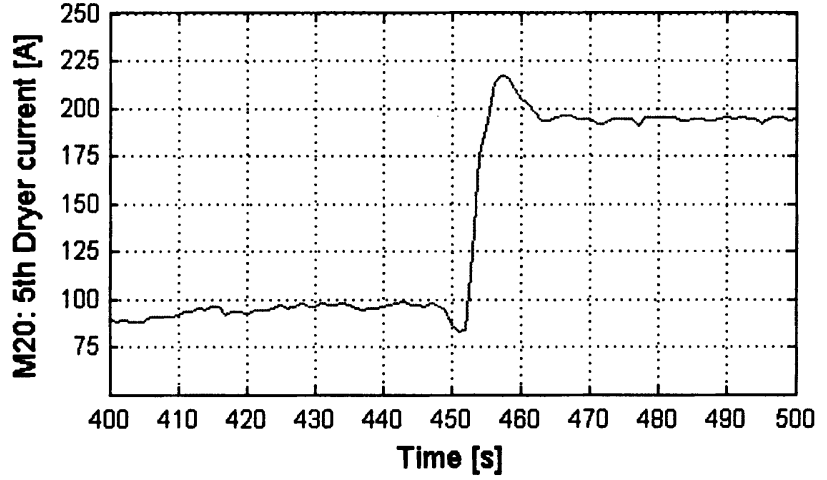

(a)

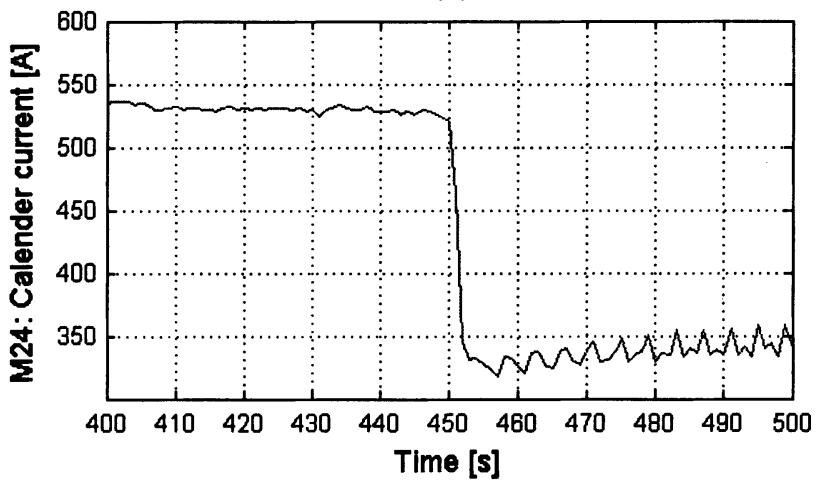

(c)

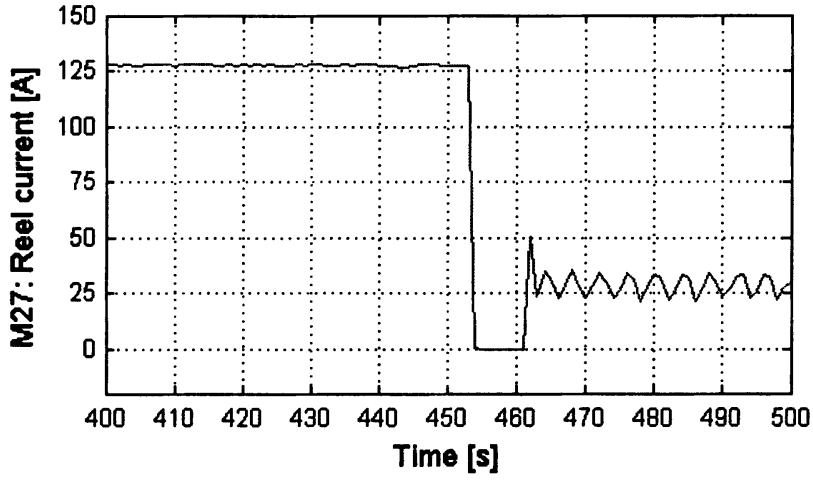

(e)

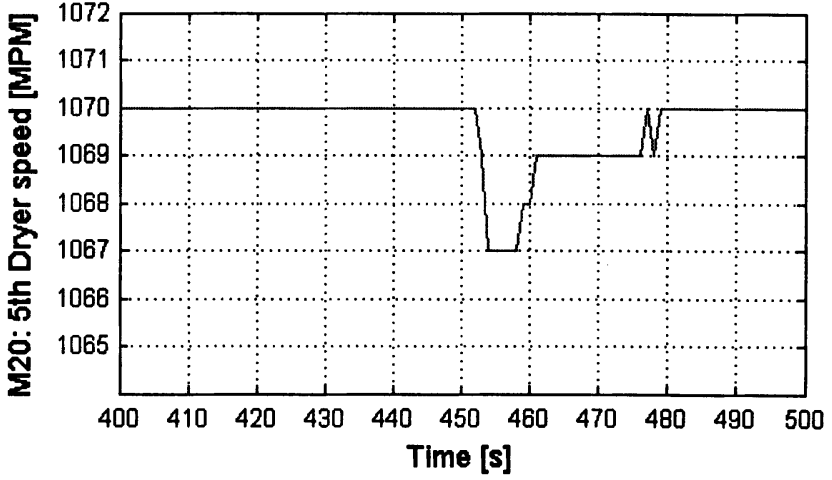

(b)

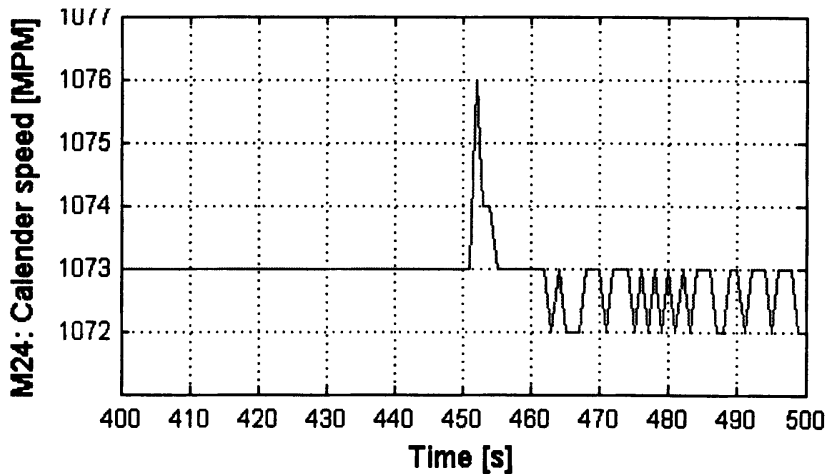

(d)

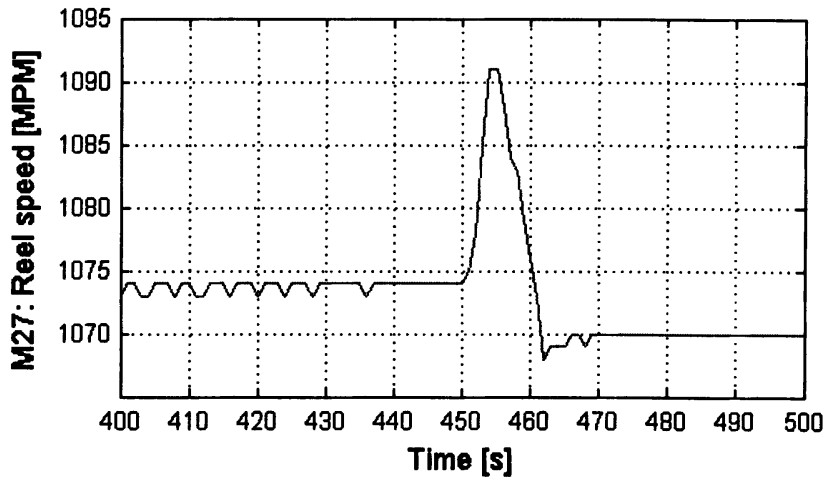

(f)

Fig. 11. Current and speed data during a sheet break. (a) Dryer current data. (b) Dryer speed data. (c) Calender current data. (d) Calender speed data. (e) Reel current data. (f) Reel speed data.

In the calender section the sequence is more complex. First, the sheet tension in the dryer-calender span disappears; current starts to decrease, and speed increases. Shortly thereafter, the sheet break detector signal switches the calender drive to speed control. Then, the break reaches the calender-reel span, the outgoing sheet tension in the calender vanishes, and the current increases up to the NRL value without tension components.

\section{EVENTS RECORDS}

In order to use actual waveforms to evaluate the event recognition algorithm design, currents and speeds were recorded during some of the events described in Section II. The paper machine used was a 1050-MPM LW paper machine which produces paper grades for newspapers and phone books. It was equipped with fully digital dc drives. The recorded waveforms include the fifth dryer (M20: $173 \mathrm{KW}$ ), the calender (M24: $475 \mathrm{KW}$ ), and the reel (M27: $155 \mathrm{KW})$. DC armature current records are taken from the current feedback transducers, and sample average velocities were computed from the digital encoders attached to each motor.

\section{A. Deactivation/Activation of Tension Control in Calender}

Tension control in the calender is usually activated by the operator at the time that the paper machine has been stabilized at the operating speed and the sheet starts to wind on the reel. When the tension control is activated, an increase in the torque (current) of the calender and a decrease in the torque (current) of the last dryer section should be expected.

Fig. 8 shows the currents in the 5th dryer (M20) and the calender (M24) drives of the LW paper machine during a 


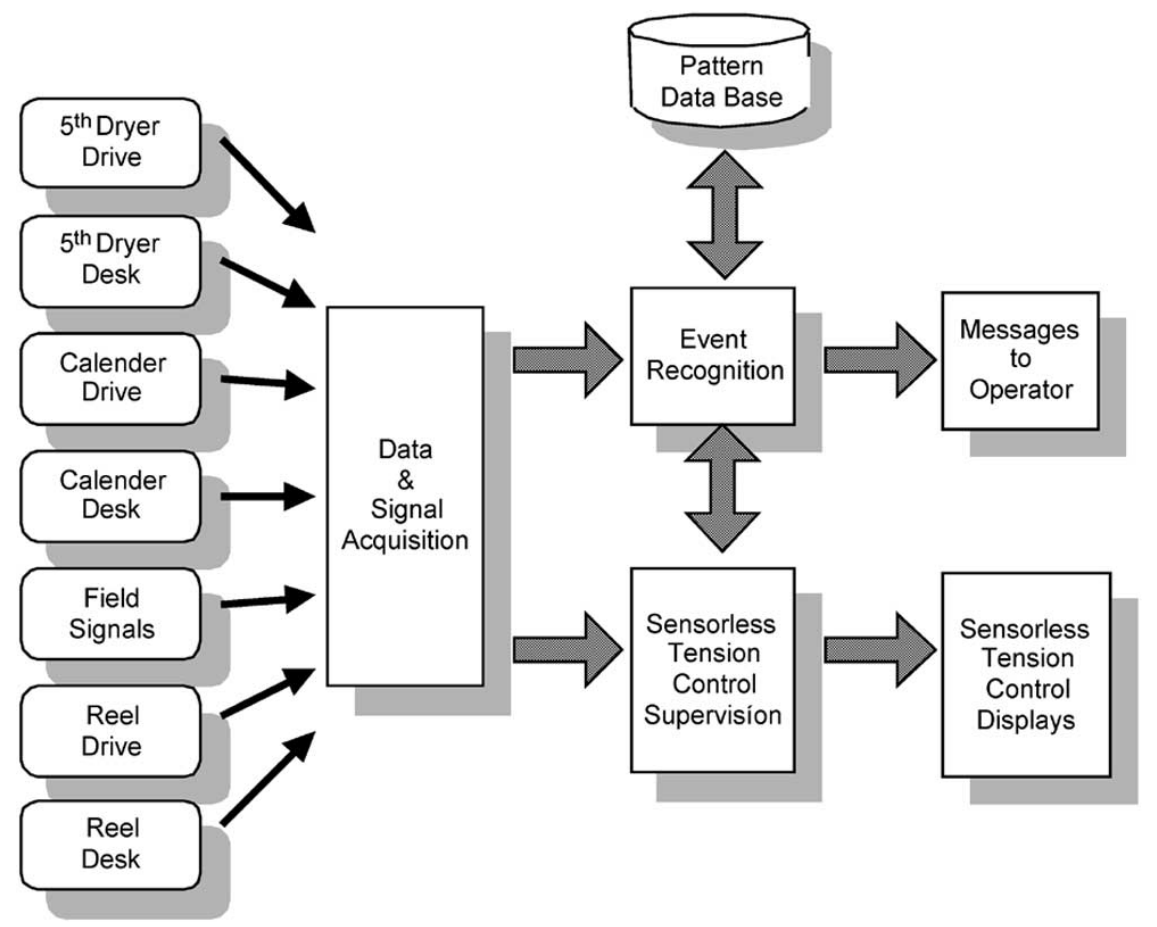

Fig. 12. Functional blocks of the expert system developed.

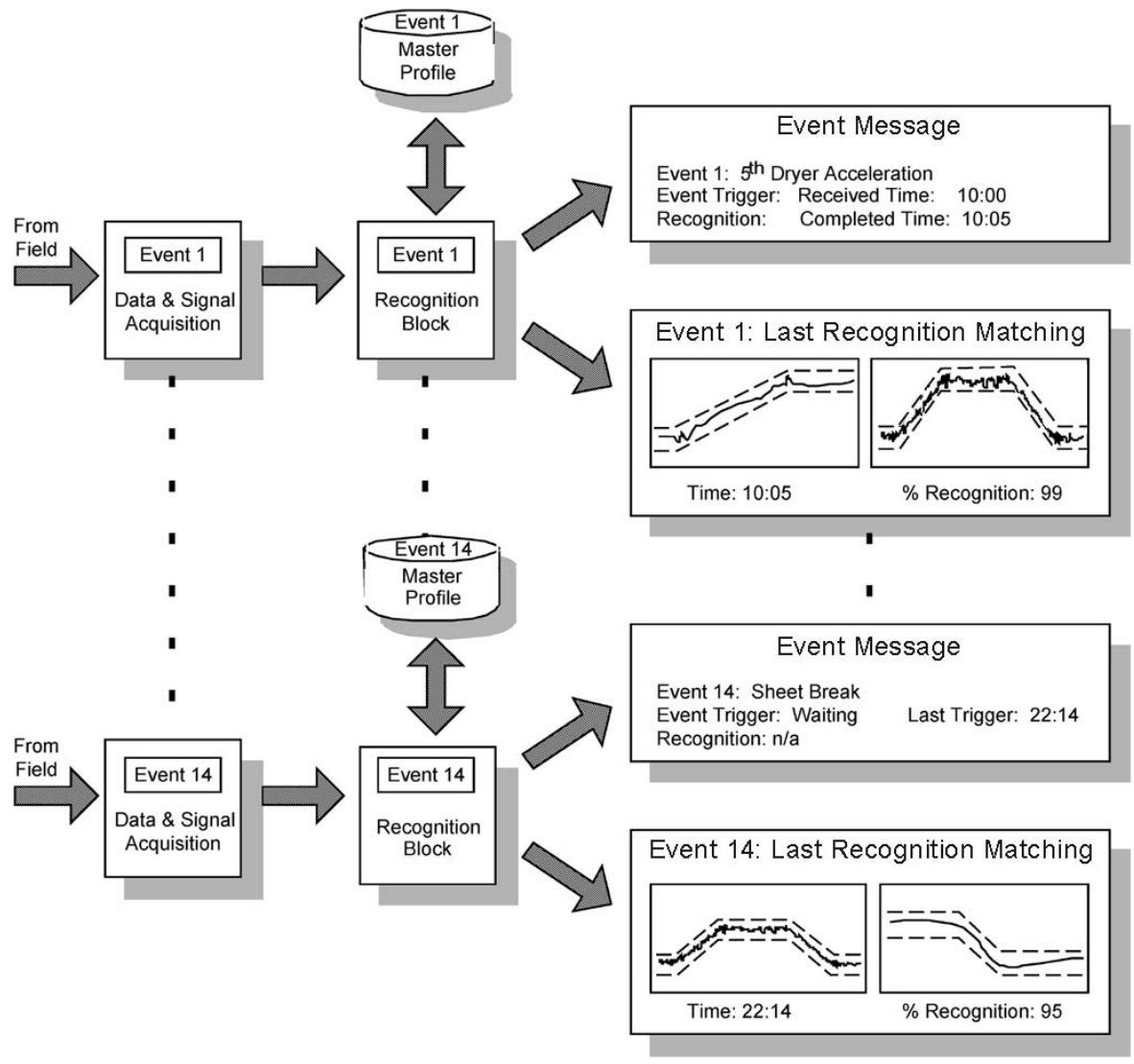

Fig. 13. Event recognition sub-blocks.

temporarily deactivation of the tension control in the calender. When the control is deactivated, the current in the fifth dryer increases, and the current in the calender decreases. As expected, sections). 


\section{B. Change of Parent Roll in Reel}

As explained earlier, the transfer of the sheet takes just a few seconds and a rapid decrease and recovery of the torque (current) in the reel drive occurs. In the calender section, a similar evolution is expected, but in the opposite sense.

Fig. 9 shows the currents in the calender (M24) and reel (M27) during the transfer to a new parent roll in the LW paper machine reel. The transient takes about $15 \mathrm{~s}$ and the current in the reel falls about $60 \mathrm{~A}$. A similar increase is shown in the current of the calender.

\section{Change of Operating Speed}

Fig. 10 shows the current and velocity waveforms of the fifth dryer (M20), calender (M24), and reel (M27) of the LW paper machine during a 100-s 10-MPM ramp rise of the operating speed. It can be seen that there are no significant changes in the currents of calender and reel drives during the ramp up, but the average current in the fifth dryer shows an increase of about $10 \mathrm{~A}$. This is consistent with the high inertia of this section, and shows that the drives accelerate at the same rate, without torque (tension) changes transferred through the sheet.

\section{Sheet Break}

During normal operating conditions, the paper machine is running at steady speed with calender and reel sections in tension control. When a sheet break occurs, it produces fast and large changes in the torque (current) of the last dryer section, calender, and reel. The section speeds will also show transient variations related to these changes.

Fig. 11 shows the current and speed waveforms in the fifth dryer (M20), calender (M24), and reel (M27) during a paper sheet break. As expected, plots show large transient changes in all currents, which produce corresponding changes in the speeds.

\section{EXPERT SySTEM DEVELOPED}

\section{A. System Concept}

The basic functional blocks of the expert system developed are shown in Fig. 12. They are the "Data \& Signal Acquisition" block, the "Event Recognition" block, and the "Sensorless Tension Control Supervision" block.

The Data \& Signal Acquisition Block receives all the signals coming from the paper machine. In this example, it is monitoring the last three sections of the paper machine and signals come from the drives (speed, current, status), the operator consoles existing in the dry end (draw, pressure and tension setting, and pushbuttons), and eventually, from some field signals (sheet break detectors, etc.). The signals are isolated, converted and stored in vectors to be used for the Event Recognition and Sensorless Tension Control Supervision blocks.

The "Pattern Data Base" stores all the master event profiles that are used for the Event Recognition block, and other profiles recorded for the operators for statistical or maintenance use. During the commissioning of the system a profile acquisition option is used to save all the recorded pattern events. These patterns can then be used to generate the master event profiles.

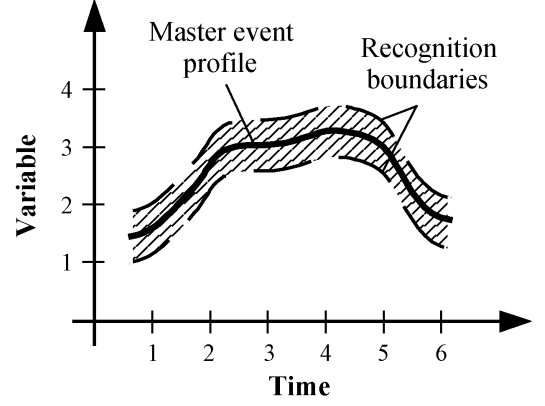

Fig. 14. Event recognition criteria.

The Event Recognition block is a core part of the system. It has the expert ability to recognize any of the ten events described in Section II. This is done by using a predefined matching algorithm, which compares the acquired signal with the corresponding master pattern. Depending on the result of this comparison and the event, appropriate messages and plots are sent to the operator.

The Sensorless Tension Control Supervision block is another core part of the system. According to the sequence of events, this block monitors the actual status of the dry-end sections, checks (in conjunction with the Event Recognition block) the drive signals during the implementation of sensorless tension control, and tracks the relevant signals of the sensorless control algorithms to assure its long-term stability. This supervision is reported on-line to the operator in a screen display.

\section{B. Event Recognition Block}

A basic task of the proposed expert system is event recognition. All the events described in Section II are included in this block. Depending of the number of sections included in the system, the same type of event could be programmed several times. For instance, a Section Acceleration Event should be included for each section.

This block is structured in parallel paths, according to the number of events programmed. Each event has its own Event Recognition sub-block and works with specific sub-blocks of the Data \& Signal Acquisition block and Master Data Base. Fig. 13 shows this structure for a 14-event system.

The basic event recognition criterion uses a master event profile and recognition boundaries (see Fig. 14). To generate these curves the system offers two options. One option is to record several events, and then define the master profile as the average of the recorded waveforms, and define the recognition boundaries as the upper and lower envelopes of the recorded waveforms. The other option is that the operator, using the recorded signals, draws linear segments to act as the master profile and recognition boundaries.

Each event recognition sub-block is activated by the related signal trigger, as described in Section II. The Data \& Signal Acquisition sub-block saves and sends data vectors which contain the drive signals related to the event. These waveforms are compared to the master and boundary profiles and the system computes the percentage of values of the newly acquired event record that lie inside the boundaries. If this percentage is over the value set by the operator, an acknowledge message is sent to 
Sensorless Tension Control Supervision

\begin{tabular}{|c|c|c|c|c|c|}
\hline \multicolumn{6}{|c|}{ Status Messages } \\
\hline $\begin{array}{ll}\square & S \\
\square & S\end{array}$ & \multicolumn{4}{|c|}{$\begin{array}{l}\text { Sensorless Tension Control Span 5th Dryer - Calender: Normal } \\
\text { Sensorless Tension Control Span Calender - Reel: Normal }\end{array}$} & \\
\hline \multicolumn{2}{|c|}{$\begin{array}{l}\text { Initial } \\
\text { Conditions }\end{array}$} & & \multicolumn{2}{|c|}{ Actual Values } & \\
\hline $\begin{array}{l}\text { 5th Dryer: } \\
\text { Current: } \\
\text { Speed: }\end{array}$ & $\begin{array}{l}\text { (A) } \\
\text { (RPM) }\end{array}$ & $\begin{array}{l}\text { 5th Dryer: } \\
\text { Current: } \\
\text { Speed: }\end{array}$ & $\begin{array}{l}\text { (A) } \\
\text { (RPM) }\end{array}$ & $\begin{array}{l}\text { Outgoing } \\
\text { Sheet Tens : }\end{array}$ & (\%) \\
\hline $\begin{array}{l}\text { Calender: } \\
\text { Current: } \\
\text { Speed: } \\
\text { Draw: }\end{array}$ & $\begin{array}{l}\text { (A) } \\
\text { (RPM) } \\
\text { (\%) }\end{array}$ & $\begin{array}{l}\text { OCalender: } \\
\text { Current: } \\
\text { Speed: } \\
\text { Tension Ref: } \\
\text { Tension Act: }\end{array}$ & $\begin{array}{l}(\mathrm{A}) \\
(\mathrm{RPM}) \\
(\%) \\
(\%)\end{array}$ & $\begin{array}{l}\text { Incoming } \\
\text { Sheet Tens : } \\
\text { Diff Tens: } \\
\text { Outgoing } \\
\text { Sheet Tens : }\end{array}$ & $\begin{array}{l}(\%) \\
(\%) \\
(\%)\end{array}$ \\
\hline $\begin{array}{l}\text { Reel: } \\
\text { Current: } \\
\text { Speed: } \\
\text { Draw: }\end{array}$ & $\begin{array}{l}\text { (A) } \\
\text { (RPM) } \\
\text { (\%) }\end{array}$ & $\begin{array}{l}\text { OReel: } \\
\text { Current: } \\
\text { Speed: } \\
\text { Tension Ref: } \\
\text { Tension Act: }\end{array}$ & $\begin{array}{l}(\mathrm{A}) \\
(\mathrm{RPM}) \\
(\%) \\
(\%)\end{array}$ & $\begin{array}{l}\text { Incoming } \\
\text { Sheet Tens : }\end{array}$ & $(\%)$ \\
\hline
\end{tabular}

Fig. 15. Sensorless tension control supervision screen.

the operator. If not, a warning message is sent. The system also has the option of displaying the waveforms of the recognition matching process. This situation is depicted in Fig. 13.

The system makes its decisions using the if-then rule property commonly found in rule-based expert systems. If the acquired curve matches the percentage of recognition set by the operator, then some specific messages are displayed and/or some specific actions are taken.

In the application of the Event Recognition block, the operator has to define the recognition boundaries, and the limit value for the percentage of recognition. There is no advantage in selecting a recognition zone that is too narrow and/or an excessively high percentage of recognition. The master profiles of each event are quite different from the master profiles of the other events, and from any other process change that could show up, so there is no risk of making a wrong event recognition. In addition, it should be noticed that each event recognition is activated by a unique trigger signal, which clearly identify the event under evaluation.

The appropriate selection of the block parameters is based on experience, so a large number of event records should be acquired. At the beginning $\pm 20 \%$ recognition boundaries can be used.

\section{Sensorless Tension Control Supervision}

In [1] the authors presented a sensorless tension control for dry-end sections of a paper machine, which is capable of estimating and controlling the sheet tension in the upstream draws of the calender and reel sections. The tension estimation algorithm uses torque commands (or torque component of currents) of the drives and is robust to load changes and reduced, or null, differential tension in central sections. Evaluation was made in the same paper machine used in Section II, and shown in Fig. 1.

The objective of the Sensorless Tension Control Supervision block of the proposed expert system is to help and assure the long-term stability of the sensorless tension control presented in [1]. This is done by monitoring the dry-end sections and:

1) using the event recognition ability of the system to keep track of the status in the dry-end sections;

2) refreshing the initial data used by the sensorless algorithms;

3) detecting any abnormal situation by cross-checking the computed values and comparing them with the historical records.

The main tasks included in this supervision are as follows.

a) Each time the paper sheet is threaded through the dry-end sections (after a sheet break or maintenance shutdown), the system records the section load currents, which are used to decouple the load torques from the sheet tension components. Values are also compared to historical records for each paper grade.

b) After each sensorless tension control loop is activated, recorded waveforms are processed by the Recognition block. Initial and final values are compared with the expected ones, according to the draw and tension settings.

c) While the sensorless tension control loops are active, the expert system cross checks the estimated sheet tension at both ends of each span. If values do not match, system gives a warning message.

d) While the paper machine runs at normal operating conditions with the calender and reel sections in sensorless tension control, the system monitors the section torques (currents), searching for any unexpected variation. Monitoring is reinitialized in every parent roll change and each torque (current) profile is compared with the master profile. If any of the waveforms depart significantly from the master profile, a warning message is given.

All the relevant values and messages of the Sensorless Tension Control Supervision block are reported in the system monitors. Fig. 15 shows a proposed arrangement for the monitor. 


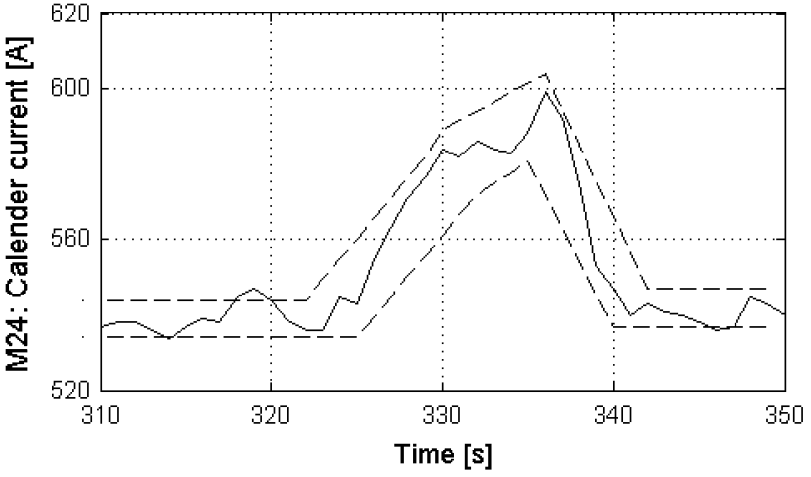

(a)

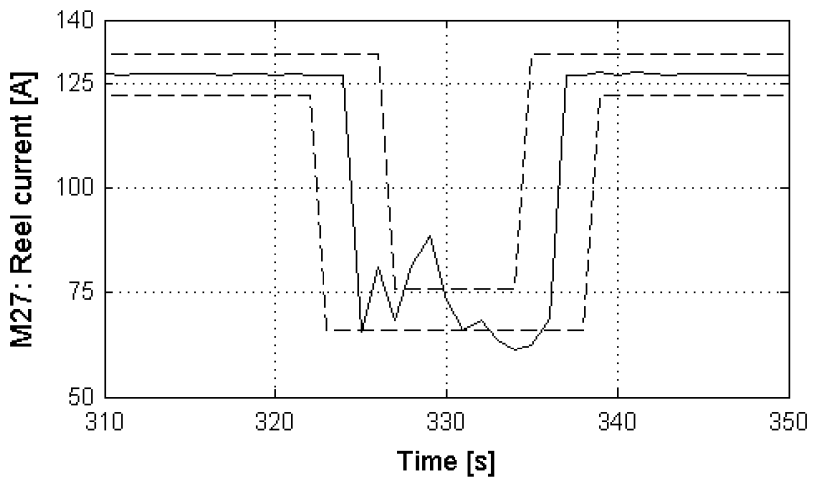

(b)

Fig. 16. Event recognition during a parent roll transfer. (a) Calender current waveform (solid lines) and designated recognition boundaries (dashed lines). (b) Reel current waveform (solid lines) and designated recognition boundaries (dashed lines).

\section{Event ReCognition EVALUation}

Using the data recorded from the paper machine described in Section III, it is possible to implement and evaluate a basic event recognition algorithm. The option selected for the master profile boundaries is the linear segment approximation. Two events are evaluated: a parent roll transfer, and an operating speed change.

Fig. 16 shows the calender and reel current waveforms during the parent roll event and, in dashed lines, the designated recognition boundaries. For these boundaries, the percentage of recognition is $95.5 \%$ for the calender current and $93.2 \%$ for the reel current.

Fig. 17 shows the event recognition plots of a change in the operating speed. Fig. 17(a) shows the ramp speed increase of the dryer section, and Fig. 17(b) shows the related armature current.

\section{CONCLUSION}

A rule-based expert system for the supervision and control of the dry-end sections of paper machines has been presented. This system has two major features: event recognition capability in the dry-end sections, and supervision of the sensorless tension control. The event recognition property is a valuable help for the operator as well as for the maintenance and supervision staff. The supervision of the sensorless tension control loops in the dry-end sections, assure the long-term stability of the estimation algorithms. It also enables early detection of mechanical problems as they begin to produce an abnormal load in any section.

As presented, this expert system does not have learning capability during normal operation. It is possible to improve its

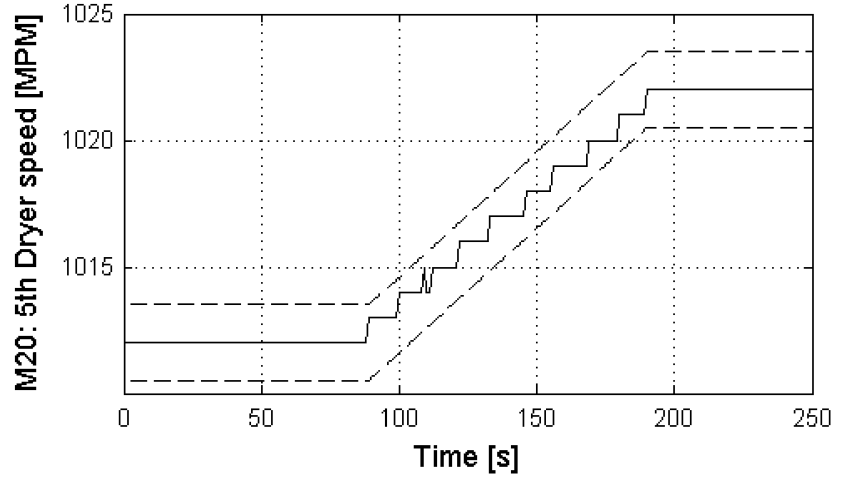

(a)

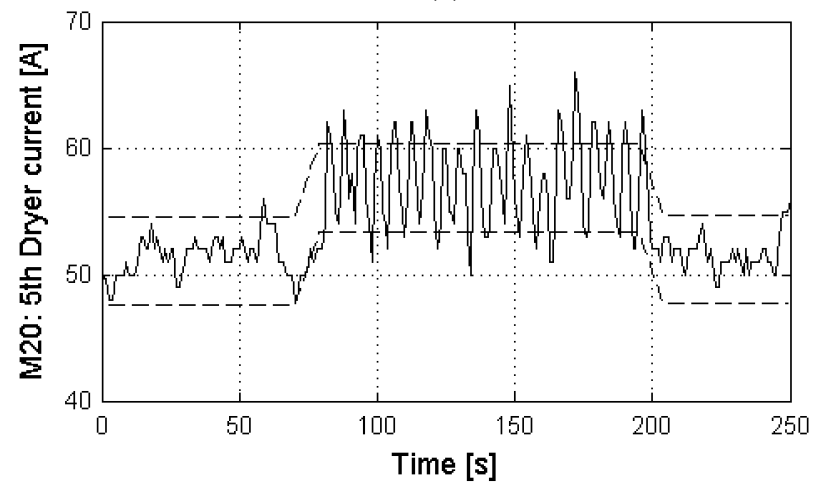

(b)

Fig. 17. Event recognition during an operating speed change. (a) Dryer speed waveform (solid lines) and designated recognition boundaries (dashed lines). (b) Dryer current waveform (solid lines) and designated recognition boundaries (dashed lines).

diagnosis capability by adding a neural learning block, which should permit dynamic updating of the master profiles, as well enabling the system to change operating routines or production programs.

\section{REFERENCES}

[1] M. A. L. Valenzuela, J. M. Bentley, and R. D. Lorenz, "Sensorless tension control in paper machines," in Conf. Rec. 2002 Annual Pulp and Paper Industry Tech. Conf., Toronto, ON, Canada, June 2002, pp. 44-53.

[2] M. Rao, X. Sun, and J. Feng, "Intelligent system architecture for process operation support," Expert Syst. Applicat., vol. 19, pp. 279-288, 2000.

[3] Q. Xia and M. Rao, "Knowledge architecture and system design for intelligent operation support systems," Expert Syst. Applicat., vol. 19, pp. 115-127, 2000.

[4] J. D. Kershner and R. D. Lorenz, "Construction techniques for factory floor expert system," ASME J. Eng. Ind., vol. 110, pp. 395-397, Nov. 1988.

[5] R. D. Lorenz, Ed., Neuro/Fuzzy Drive/Motion Control. Madison, WI: WEMPEC Publishing Services, Sept. 1995.

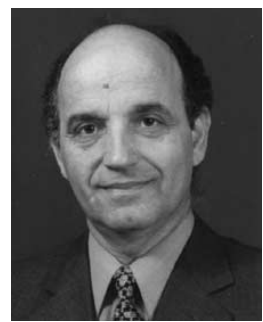

M. Aníbal Valenzuela (M'93-SM'01) received the electrical engineering degree and the Masters degree in electrical engineering from the University of Chile, Santiago, Chile, in 1976 and 1978, respectively.

Since 1978, he has been with the Department of Electrical Engineering, University of Concepción, Concepción, Chile, where he is an Associate Professor in the area of electric machines and drives. His current research interests include motion control of multidrive systems, sensorless control of ac drives, and thermal evaluation of induction motors. 


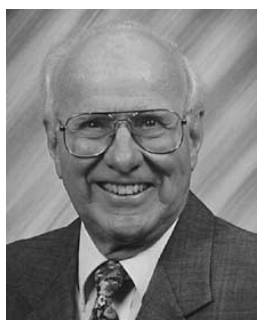

John Martin Bentley (M'54-SM'83-LS'94-LF'99) received the B.S. degree in electrical engineering from Pennsylvania State University, University Park, in 1951.

From 1951 to 1984 , he was with Westinghouse Electric Corporation, Pittsburgh, PA, and Buffalo, NY. He was awarded the company's high engineering position of Fellow, and became recognized as an authority in the field of automatic control and drive systems for the paper industry worldwide, including the first digital sectional and winder drives in North America. From 1984 to 1991, he was Principal Engineer with Allen-Bradley/Stromberg in the Milwaukee, WI, area, and was responsible for in-depth technical and marketing guidance to this multinational joint venture. During this period, he was instrumental in introducing the ac vector drive system to the North American market. Over 1000 sections, totaling approximately $200000 \mathrm{hp}$ were applied on sectional, winder, and finishing equipment drives, including the first sectional ac paper machine drive in North America. From 1991 until his retirement in 1996, he was Principal Engineer with ABB Industrial Systems Inc., New Berlin, WI, and ABB Industry OY, Helsinki, Finland. He provided application and design guidance to the worldwide ABB Pulp and Paper Systems Drives organization, primarily in the area of high-performance ac drive and control systems. He has also been an author and instructor in his areas of expertise for many years. Since his 1996 retirement from $\mathrm{ABB}$, he has continued to consult on a part-time basis, providing expertise in the areas of electromechanical influences on high-performance drive systems, cable and grounding techniques for controlling ac drive system induced common-mode currents, and general guidance for the selection and application of high performance ac drive systems.

Mr. Bentley was recognized for his professional contribution within the Technical Association of the Pulp and Paper Industry (TAPPI) through the TAPPI Engineering Division Award and the E. H. Neese Prize in 1981. A similar honor was acknowledged from the IEEE Industry Applications Society as he was a recipient of the Pulp and Paper Industry Committee Meritorious Achievement Award in 1979. He was appointed to the status of TAPPI Fellow in 1986, and in 1999 was elected as an IEEE Fellow "For contributions to the application an design of electrical drive systems in the pulp and paper industry." The Fellow status is one of the most prestigious honors bestowed by TAPPI and IEEE, and he is the only living member that has been awarded the Fellow status by both organizations

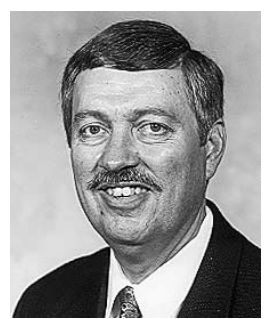

Robert D. Lorenz (S'83-M'84-SM'91-F'98) received the B.S., M.S., and Ph.D. degrees from the University of Wisconsin, Madison, and the M.B.A. degree from the University of Rochester, Rochester, NY.

Since 1984, he has been a member of the faculty of the University of Wisconsin, Madison, where he is the Mead Witter Foundation Consolidated Papers Professor of Controls Engineering in both the Department of Mechanical Engineering and the Department of Electrical and Computer Engineering. He is Co-Director of the Wisconsin Electric Machines and Power Electronics Consortium, which celebrated its 20th anniversary in 2001. It is the largest industrial research consortium on motor drives in the world. He is also the thrust leader for control and sensor integration in the Center for Power Electronic Systems, an NSF Engineering Research Center (ERC) which is a joint ERC with Virgina Polytechnic Institute and State University, Rensselaer Polytechnic Institute, University of Puerto Rico-Mayaguez, and North Carolina A\&T. From 1972 to 1982, he was a member of the research staff at the Gleason Works, Rochester, NY, working principally on high-performance drives and synchronized motion control. He was a Visiting Research Professor in the Electrical Drives Group, Catholic University of Leuven, Leuven, Belgium, in the summer of 1989 an in the Power Electronics and Electrical Drives Institute, Technical University of Aachen, Aachen, Germany, in the summers of 1987, 1991, 1995, 1997, and 1999, where he also was the SEW Eurodrive Guest Professor from September 1, 2000 until July 7, 2001. In 1969-1970, he conducted Master thesis research in adaptive control of machine tools at the Technical University of Aachen. His current research interests include sensorless electromagnetic motor/actuator technologies, real-time signal processing and estimation techniques, precision multiaxis motion control, and ac/dc drive and high-precision machine control technologies. He has authored more than 160 published technical papers and is the holder of 16 patents, with two more pending.

Dr. Lorenz was the IEEE Industry Applications Society (IAS) President for 2001, a Distinguished Lecturer of the IAS for 2000/2001, immediate past Chair of the IAS Awards Department, and past Chairman of the IAS Industrial Drives Committee, and is a member of the IAS Industrial Drives, Electric Machines, Industrial Power Converter, and Industrial Automation and Control Committees. $\mathrm{He}$ is also the current Chair of the Periodicals Committee for the IEEE Technical Activities Board. He is a member of the IEEE Sensor Council AdCom. He was awarded the 2003 IEEE IAS Outstanding Achievement award, which honors his outstanding contributions and technological developments in the application of electricity to industry. He has won 15 prize paper awards. He is a Registered Professional Engineer in the States of New York and Wisconsin. 